$$
\begin{gathered}
\text { 경관협정의 지속성을 위한 성 공요소 도출 } \\
\text { - 옹진군 문갑도와 수원시 거북시장길 사례분석을 통하여 - } \\
\text { 박혜은 }
\end{gathered}
$$

충남연구원 공공디자인센터 책임연구원

\title{
Derivation of Success Elements for the Sustainability of Landscape Agreements - A Case Study on Ongjin-gun Mungab Island and Suwon Gobuk Market -
}

\author{
Park, Hye-Eun \\ Senior Researcher, Public Design Center, ChungNam Institute
}

\begin{abstract}
This study shows that the role of residents in landscape management is becoming increasingly important. The purpose of this study is to suggest elements that can continue the operation of landscape agreements and directions for promoting them. Therefore, 1)the operational elements considering the sustainability of the landscape agreements were proposed by way of literature research, expert interviews, and surveys. 2)The sustainable operation of elements of the landscape agreement were applied and best practices were developed through interviews with participants and literature analysis. 3)The final plan operational elements considering the sustainability of the landscape agreements and the directions for implementation were presented. As for the results, it was first presented that the elements of continuous operation of the landscape agreement, consisted of 3 major categories, 10 subcategories, and 25 details. These include resident awareness, practical applicability, effectiveness of administrative means, securing the budget, maintenance, public relations, expert support, dedicated support organization, sustainability of participation, and resident participation and communication methods. It is a detailed list of items that should be considered in the preparation phase, maintenance phase, and conclusion phase. Second, it suggested the direction for the sustainable operation of the landscape agreements be highly backed by the residents, and after reaching consensus on a landscape agreement, it is necessary that the agreement is based on contents that the residents can execute themselves. In addition, it was found that there is a need for a system to prepare the basis for securing the budget for the continuity of work, preparation of the landscape agreements, and consultation and activity costs during the maintenance phase. In addition, continuous exchanges and capacity building among residents have signed landscape agreements, and step-by-step support from experts in accordance with the level of involvement of residents is necessary. Third, even if a landscape agreement is concluded in connection with public projects, it is understood that the residents have the capacity to participate and can continue to support the administration and experts to enable the continued operation of the landscape agreement.
\end{abstract}

Key Words: Landscape Agreement, Sustainability, Success Elements, Landscape Agreement Phase, Participant Group

\footnotetext{
${ }^{\dagger}$ : 이 논문은 2017년 충남연구원 공공디자인센터 연구과제 “충청남도 농촌경관협정 추진방안”의 일부를 보완 발전시킨 것임. Corresponding author: Hye-Eun Park, Senior Researcher, Dept. of Public Design Center, ChungNam Institute, Gongju 32589, Korea, Tel.: +82-41-840-1258, E-mail: hyeeu@cni.re.kr
} 


\section{국문초록}

본 연구는 경관관리에서 주민의 역할이 점차 중요해지고 있는 가운데, 경관협정이 지속적으로 운영될 수 있는 성공요소 도출 및 이를 추진하기 위한 방향을 제시하는 것이 목적이다. 이에, 1) 문헌조사 및 전문가 인터뷰 조사를 통해 경관협정의 지속성을 고려 한 성공요소(안)을 제시하였고, 2) 참여주체 인터뷰 조사 및 문헌분석을 통해 경관협정의 지속적 운영의 성공요소(안)을 선진사례 에 적용한 후, 경관협정의 지속성을 위한 성공요소의 최종안과 이에 대한 추진방향을 제시하였다. 그 결과, 첫째, 3 개의 대분류와 10 개의 중분류, 25 개의 세부항목으로 구성된 경관협정의 지속적 운영 성공요소를 제시하였다. 이것은 주민의지, 실현가능성, 행정 수단의 실효성, 예산확보, 유지관리, 홍보, 전문가 지원, 전담지원 조직, 참여의 지속성, 주민참여 의사소통방식에 대한 내용이며, 경 관협정 체결 준비단계, 체결단계, 유지관리단계에서 전반적으로 고려해야 하면서도 구체적인 세부항목이다. 둘째, 경관협정 지속적 운영의 추진방향을 제시하였다. 경관협정 체결은 주민의지가 높으며 경관협정에 대한 공감대가 형성된 이후에 주민들 스스로 지킬 수 있는 내용 중심으로 하고, 행정 담당자의 업무 지속성, 경관협정 체결준비부터 유지관리단계에 소요되는 자문비 및 활동비의 예 산확보 근거 마련을 위한 제도가 필요하다. 그리고 경관협정 체결자인 주민들 간 지속적인 교류 및 역량강화, 이를 위한 주민참여 역량 정도에 맞는 전문가의 단계별 지원과 이를 근거할 수 있는 제도도 역시 필요하다. 셋째, 공공사업과 연계하여 경관협정을 체결 하더라도 주민참여 역량이 갖춰져 있는 곳의 대상 지원 여부, 주민참여 경관관리가 가능하도록 행정과 전문가의 지속적 지원 여부가 경관협정의 지속적 운영에 영향을 미칠 수 있다는 것을 알 수 있었다. 본 연구는 사례분석에 있어서 두 곳을 대상으로 한 한계점을 가지고 있으며, 성공하지 못한 사례를 포함한 다양한 사례분석을 통한 보다 더 심층적인 연구는 향후 과제로 남겨두고자 한다.

주제어: 경관협정, 지속성, 성공요소, 경관협정 단계, 참여주체

\section{I. 서론}

\section{1. 연구의 배경 및 목적}

2007년에「경관법,이 제정되면서 경관의 사회적 가치에 대 한 인식이 점차 높아지고 있는 가운데, 기존 경관자원을 보 전 · 관리 · 형성하기 위해 주민중심의 경관관리 활동에 중점을 두는 패러다임으로 전환되고 있다. 이에, 최근 주민의 자발적 참여를 통해 경관을 보존 및 형성하면서 지역 여건과 특성에 맞는 경관관리를 위한 방법으로서 경관협정에 대한 관심이 높 아지고 있다.

경관협정은 첫째, 지역 문화를 반영하고 유지할 수 있는 생 활습관 등 주민활동까지 포함할 수 있기 때문에 지역의 특성을 반영한 경관관리가 가능하다. 기존에 지구단위계획이나 기타 조례에서 다루기 어려웠던 주민활동을 경관관리 방법으로 활 용함으로써 지역 고유의 특성을 반영한 경관을 창출 및 보존할 수가 있다. 둘째, 건축물 외관, 옥외광고물, 개인 사유지 이용 등 개인의 재산권 침해라는 이유로 그간 공공의 개입에 한계가 있었던 사적영역을 협정의 대상에 포함할 수 있다. 경관은 공 적영역은 물론 지역의 경관을 형성하는 중요한 요소들인 사적 영역을 포함하여 종합적인 개선과 관리가 필요하다. 셋째, 경관 관련 사업 후 경관협정을 통해 유지관리가 가능하다. 사업 완 료 후 유지관리 및 지속가능성에 대한 문제가 지속적으로 제기 됨에 따라 최근에는 공모사업 선정 시에 주민참여 또는 주민역 량강화 등 유지관리 방안이 매우 중요시되고 있다. 경관협정은
주민 스스로 경관을 보존하고 유지관리할 수 있는 제도로서 유 지관리의 지속가능성에 의미가 있다.

이러한 경관협정의 필요성이 커지면서 중앙부처 및 지자체 에서는 시범사업으로 경관협정 체결을 지원하거나 또는 타 사 업과 연계하여 추진하도록 유도하는 등 경관협정을 활성화하 기 위한 노력을 하고 있다. 하지만 이러한 노력에도 불구하고, 2017년 기준 경관협정을 체결한 39곳 중 유지되고 있는 곳은 17 곳에 불과한 실정이다. 이에 대하여 주민참여 공감대 및 의 식 부족, 관 주도의 추진방식 등의 문제제기를 비롯하여, 경관 협정이 우리나라의 여건에 부합한지 제도의 적용 적합성 문제 도 제기되고 있다. 그렇지만 이러한 상황속에서도 경관협정에 대한 관심은 점차 커지고 있으며, 경관협정을 체결하는 사례가 꾸준히 나오고 있다.

본 연구에서는 최근 관심이 높아지고 있는 경관협정을 추진 함에 있어서 주민참여 경관협정이 지속성을 가지고 성공적으 로 운영할 수 있는 요소 및 이를 추진하기 위한 방향을 제시하 고자 한다.

\section{2. 연구의 방법 및 범위}

본 연구는 경관협정의 지속성을 고려한 요소와 추진방향을 제시하기 위해 3 단계로 진행하였다. 1 단계는 경관협정 개념 및 추진현황을 검토하였다. 2 단계는 선행연구 분석을 통해 경관협 정의 지속적 운영에 필요한 과제들을 도출하고, 전문가 대상 인터뷰 조사를 하여 경관협정을 위한 지속적 운영요소(안)을 
제시한다. 3 단계에서는 제시한 경관협정의 지속적 운영요소 (안)을 경관협정 체결 이후 지속적으로 운영하고 있는 사례 에 적용해봄으로써, 운영요소의 최종안과 운영요소별 추진방 향을 제시하였다(Figure 1 참조). 이를 위해 각 사례의 경관 협정 추진 관련 내부문서를 포함하여 각종 자료의 문헌분석, 경 관협정 참여주체 대상 인터뷰 조사를 실시하였다(Table 1 참조)

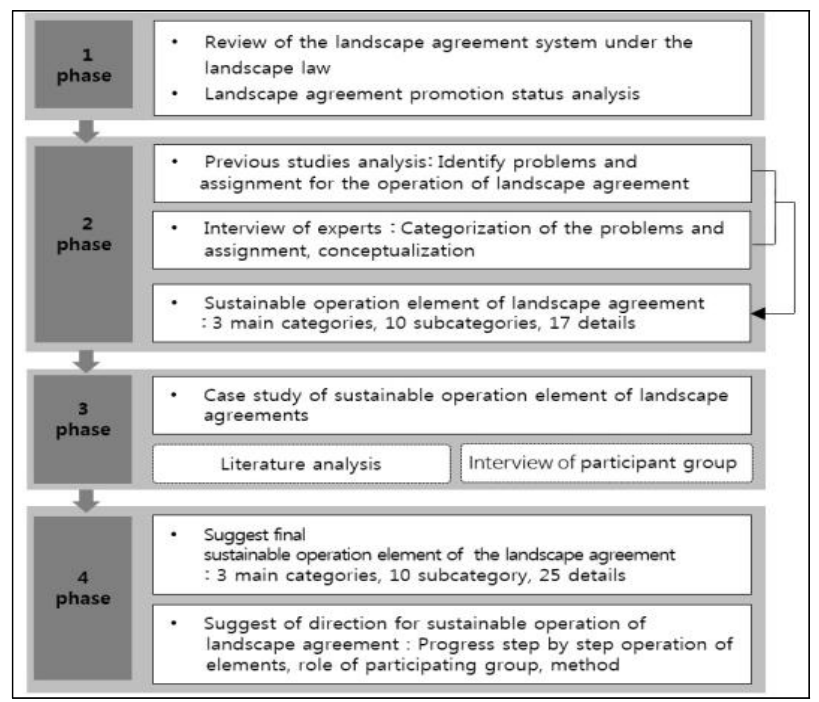

Figure 1. Research process

Table 1. Research analysis method

\begin{tabular}{c|l}
\hline Method & \multicolumn{1}{c}{ Contents } \\
\hline \multirow{3}{*}{$\begin{array}{c}\text { Literature } \\
\text { Analysis }\end{array}$} & $\begin{array}{l}\text { - Previous studies analysis of landscape agreement } \\
\text { Landscape ordinance of ongjin and Suwon, landscape agree- } \\
\text { ment, contents of landscape agreement, internal documents } \\
\text { and materials in the process of signing the landscape } \\
\text { agreement }\end{array}$ \\
\hline $\begin{array}{c}\text { Interview } \\
\text { of experts }\end{array}$ & $\begin{array}{l}-2 \text { persons(planning and architecture, local planning), 2017. 09. } \\
\text { alization }\end{array}$ \\
\hline $\begin{array}{c}\text { Interview of } \\
\text { participant } \\
\text { group }\end{array}$ & $\begin{array}{l}\text { - Propulsion motivation, reasons for selecting district, conscious- } \\
\text { ness of residents, contents of landscape agreements, contents } \\
\text { and motivation of administrative support, regulatory methods } \\
\text { in case of violations, communication methods, expert support, } \\
\text { achievements and problems, etc. }\end{array}$ \\
\hline- Method: Interview after analyzing literature
\end{tabular}

\section{II. 이론적 고찰}

\section{1. 경관협정 개념 및 현황}

1)「경관법,상 경관협정제도

경관협정 체결은 토지소유자, 건축물 소유자, 지상권자, 토지
소유자 및 건축물소유자의 동의를 받은 자로 규정하고 있으며, 지자체 조례를 통해 해당 토지 및 건축물의 관리자, 점유자, 임 차인 등 토지 또는 건축물을 사용할 권리가 있는 사람도 포함 하고 있다. 경관협정에 포함하고 있는 사항은 건축물의 의장 . 색채 및 옥외광고물, 공작물 및 건축설비의 위치, 건축물 및 공 작물의 외부공간, 지역의 토지보전 및 이용, 역사·문화 경관 관리 및 조성 등이며, 이 외에 지자체 조례에서 내용을 추가할 수 있다. 이것은 지역의 문화와 사회적인 요소가 드러나지 않 는 물리적인 요소로 볼 수 있으나, 이를 유지하기 위한 주민들 의 의지와 참여가 전제되어야 하며, 경관 유지 및 향상을 위해 쓰레기 관리 및 마을 청소, 화분 및 녹지 관리, 보행 안전, 커뮤 니티 활동 등 주민활동까지 포함된다.

이 외에도 경관협정서 작성내용, 경관협정 추진 및 운영을 위한 경관협정운영회 설립, 경관협정 인가·변경·폐지, 경관 협정의 준수 및 승계, 경관협정 지원에 관하여 규정하고 있다. 경관협정서를 경관위원회의 심의절차 이후에 인가하도록 규정 하고 있으며, 변경이나 폐지 시에도 동일한 절차에 의해 진행 하도록 하고 있다. 특히, 경관협정서 작성 및 경관협정을 위한 사업에 대하여 기술적 및 재정적 지원이 가능하도록 규정함으 로써, 경관협정의 체결과 이행이 원활히 이루어지도록 법적 근 거를 마련해 놓고 있다.

\section{2) 경관협정 추진현황}

경관협정은 우리나라와 유사한 제도적 체계를 가진 일본의 「경관법」을 참고로 한 것이다. 일본은 1970년대 초부터 지자체 자주조례를 운용하고 있었으며, 조례의 법적 근거를 마련하기 위해 2004년에 r경관법」을 제정하였다. 이와 달리 우리나라의 경우에는 지자체의 경험이 쌓이지 않은 상황에서 법 제정이 선 행되었으며, 특히 주민들이 스스로 경관활동에 참여하겠다는 의지와 행동이 수반되어야 가능한 경관협정제도의 실효성에 대한 우려는 도입초기부터 제기되어 왔다(Lee, 2016).

2017년 기준으로 경관협정을 체결한 사례는 39곳이며, 이중 체결을 유지하고 있는 곳은 17 곳 $^{1}$ 이다. 체결을 유지하고 있는 곳이 적은 이유는 경관협정이 대부분 공공 주도의 시범사업 또 는 연계사업으로 추진되는 경우가 많아, 주민의 경관협정에 대 한 이해와 공감대가 충분히 형성되지 못한 채 사업이 완료되어, 경관협정에 대한 관심 역시 없어지게 되는 것을 들 수 있달. 2017년 기준 5년 이상 협정 체결을 유지하고 있는 곳은 5 곳 ${ }^{3}$ 이 다. 이 중 도서지역에서 우리나라 최초로 경관협정을 체결하여 주변지역에까지 경관협정을 전파하고 있는 인천 옹진군 문갑 도, 3 년 6 개월이라는 기간동안 주민들의 경관협정에 대한 이해 와 공감대를 이끌어내어 협정을 체결하고, 현재 주민들이 다양 한 활동을 추진하고 있는 수원시 거북시장길은 우리나라의 선 도적 사례로 꼽히고 있다. 거북시장길이 경관협정을 목적으로 추진된 사례들 중 가장 오랫동안 지속되고 있는 사례라 한다면, 
Table 2. Previous studies analysis of landscape agreement

\begin{tabular}{|c|c|c|}
\hline Division & esearcher fellow & Contents \\
\hline \multirow{2}{*}{$\begin{array}{l}\text { Effect and } \\
\text { applicability }\end{array}$} & Park et al.(2010) & $\begin{array}{l}\text { - Analysis of the possibility of landscape agreement as a way to improve old retirement housing in Junggok 4-dong, } \\
\text { Gwangjin-gu }\end{array}$ \\
\hline & Jung and Shin(2014) & - Analyze the process of community formation in the phased process of landscape agreement \\
\hline \multirow{3}{*}{ Governance } & Kim et al.(2010) & $\begin{array}{l}\text { - Suggest ways to promote landscape agreements as sustainable landscape management through the composition, role } \\
\text { and agreement process of participating groups in the Goyang City landscape agreement project }\end{array}$ \\
\hline & $\operatorname{Kim}(2010)$ & $\begin{array}{l}\text { - Comparative analysis of the governance process of various participants through examples of Gwangjin-gu and } \\
\text { Gangbuk-gu landscape agreement projects }\end{array}$ \\
\hline & Ko et al.(2016) & $\begin{array}{l}\text { - Analysis of the communication technique and role of each participant in the process of the agreement through } \\
\text { literature research and interview survey focusing on the case of the Gobuk Market in Suwon }\end{array}$ \\
\hline \multirow{5}{*}{ Operating } & Pyon (2010) & $\begin{array}{l}\text { - To find out the problems and solutions in the operation process through case analysis for efficient operation of } \\
\text { landscape agreements }\end{array}$ \\
\hline & Lee et al.(2011) & $\begin{array}{l}\text { - Present achievements and problems through analysis of similar cases of landscape agreements } \\
\text { - Suggest concrete plan for operating of landscape agreement }\end{array}$ \\
\hline & Park et al.(2015) & $\begin{array}{l}\text { - Analysis of Mungap Island in Ongin-gun, Incheon with characteristics of effectiveness, flexibility and sustainability } \\
\text { as a llandscape agreement }\end{array}$ \\
\hline & Lee(2016) & - Present the assignment through analysis of the status of the conclusion of landscape agreements started in 2009 \\
\hline & Lee and Shim(2017) & $\begin{array}{l}\text { - Present the limitations of each operational phase through analysis of the operation status of } 28 \text { landscape agreement } \\
\text { conclusion sites }\end{array}$ \\
\hline
\end{tabular}

문갑도는 공공사업의 유지관리를 위해 공공 주도에 의해 추진 된 사례들 중 가장 오랫동안 지속되고 있는 사례로서, 본 연구 에서는 이 두 사례를 통하여 서로 다른 방식과 내용으로 경관 협정을 체결하였지만 주민참여 경관협정이 지속적으로 운영될 수 있는 방향을 도출하고자 한다.

\section{2. 선행연구 분석}

그동안 진행된 경관협정 관련 연구는 우선 경관협정제도가 우리나라에 도입되면서 시범적으로 운영된 사례분석을 통해 적용 및 확대 가능성을 제시한 연구가 진행되었다. 그리고 2009년부터 서울, 고양 등에서 경관협정이 추진되면서 이들 사 례분석을 통해 행정, 전문가, 주민의 참여주체 역할을 제시한 거버넌스 관련 연구들이 진행되었다. 최근에는 경관협정 사례 가 많아지고 관심이 높아지면서 제도의 운영 및 활성화를 위해 경관협정 운영 실태를 분석하여 개선방안을 제시하는 연구가 많아지고 있다(Table 2 참조).

Park et al.(2010)은 경관협정은 주민참여 증진 및 통합적인 환경개선이 가능하나, 경관협정제도 행정절차의 복잡함과 위반 시 제재사항 미비 등 제도가 가지는 한계를 지적하고 있다. Jung and Shin(2014)은 경관협정은 공동체 역량 강화와 공유 자산 축적 가능성 등 효과를 언급하고 있다. 거버넌스 측면에 서는 경관협정 추진과정 분석을 통해 참여주체의 역할을 제시 한 Kim et al.(2010), Kim(2010), Jung and Shin(2014)의 연구 에서 전문가의 역할과 지원의 필요성을 제시하고 있다. 특히 $\operatorname{Kim}(2010)$ 은 전문가뿐만 아니라, 담당 공무원, 지역주민대표 역시 적극적인 활동과 지원이 필요함을 제시하고 있으며, $\mathrm{Kim}$ et al.(2010)은 지역여건 및 주민의식도에 따른 다양한 의사소 통방식으로 주민참여를 유도할 것을 언급하고 있다. 운영 측면 에서 진행된 연구에서는 사업 후 유지관리 미흡, 사업 위주 진 행으로 주민 간 공감대 형성 부족, 공공사업 추진에 따른 갈등 등 한계를 지적하고 있다. 이에 대한 대안으로 Lee and Shim(2017)은 초기 활동비 및 전문가 지원 마련, 사업완료 후 모니터링 체계 구축을 언급하고 있으며, 이 외의 연구들에서 전문가와 행정의 지속적 지원, 경관협정 전담 행정 인력 필요, 주민교육 및 홍보, 주민리더 양성, 경관협정제도 활성화를 위한 사회분위기 조성 노력의 필요성을 언급하고 있다.

앞서 언급한 바와 같이, 우리나라에서의 경관협정은 주민 스 스로 하기에 주민참여 경험 기간이 짧고, 제도의 행정절차가 복잡하여 지금까지 제도에 관심과 필요성을 인식한 공공 및 전 문가 주도로 추진되어 왔다. 대부분의 사례가 체결자인 주민들 이 지역 경관을 유지관리하기 위한 목적보다는 주로 사업예산 을 확보하기 위한 수단으로 활용되어 왔던 것은 부인할 수 없 다. 경관협정을 활성화하기 위해서 앞에서 언급된 한계와 문제 점, 그리고 이를 해결하기 위한 대처방안이 필요한 시점이다.

\section{III. 경관협정의 지속적 운영 성공요소안) 제시}

앞에서 제시하고 있는 선행연구에서 경관협정 운영 시 문제 점 및 과제를 열거한 결과, 총 35 개 항목이 제시되었다(Table 3 참조). 이를 경관협정에 참여했던 전문가 인터뷰를 토대로 항목 의 유사성을 검토하여 범주화하고, 이를 대표할 수 있는 개념어 를 제시하였다. 
항목별 내용 검토 결과, 10 개로 범주화 할 수 있었다. 이는 주민의지, 실현가능성, 행정수단의 실효성, 예산확보, 유지관리, 홍보, 전문가 지원, 전담지원조직, 참여의 지속성, 주민참여 의 사소통방식이다.

이 중 주민의지와 실현가능성에 해당되는 항목들은 경관협 정에 대한 주민의지가 있으면서, 경관협정의 이해와 주민들 간 공감대가 형성되어 있고, 실제로 실천 가능한 내용 중심의 경 관협정을 추진하고자 하는 경관협정 체결 대상지 선정에 대한 내용으로 묶을 수 있다. 그리고 경관협정 체결 및 유지에 필요 한 법 제도적 측면에서의 행정수단, 예산확보, 유지관리, 경관 협정의 홍보와 관련된 항목들은 제도의 내용으로 묶을 수 있으 며, 경관협정 체결의 사전단계부터 유지관리단계까지 전문가,
행정, 주민의 역할과 협력을 내용으로 하는 항목들은 참여주체 로 묶을 수 있다.

즉, 선행연구에서 제시된 문제점 및 과제는 크게 3 개의 대분 류와 10 개의 중분류로 구분할 수 있다. 그리고 각 대분류와 중 분류에 포함되는 항목 간 유사성 및 중복성을 검토하여 17 개의 세부항목으로 구성하였다. 결과적으로 경관협정의 지속적 운영 요소(안)으로 대분류 대상지 선정에는 주민의지와 실현가능성 의 2개 중분류, 공적영역 대상 지원, 주민의 의지, 경관협정 개 념 인식 및 공감대 형성의 3 개 세부항목, 제도의 대분류에는 행 정수단의 실효성, 예산확보, 유지관리, 홍보의 4 개 중분류와 인 센티브, 위반 시 제재 조치, 행정절차상 어려움, 주민의 자부담, 주민의 자발적 재원 조성, 전문가 지원 및 협정준비를 위한 예

Table 3. Categorization of the problems and assignment of landscape agreements derived from previous studies

\begin{tabular}{|c|c|c|c|c|c|c|c|c|c|c|c|}
\hline \multirow[b]{2}{*}{$\begin{array}{c}\text { Researcher } \\
\text { fellow }\end{array}$} & \multirow[b]{2}{*}{ Problem and assignment } & \multicolumn{2}{|c|}{ Regional selection } & \multicolumn{4}{|c|}{ System } & \multicolumn{4}{|c|}{ Participant group } \\
\hline & & $\begin{array}{c}\text { Resident } \\
\text { awareness }\end{array}$ & $\begin{array}{c}\text { Practical } \\
\text { applica- } \\
\text { bility }\end{array}$ & $\begin{array}{c}\text { Effectiveness } \\
\text { of } \\
\text { administrative } \\
\text { means }\end{array}$ & $\begin{array}{l}\text { Securing } \\
\text { budget }\end{array}$ & $\begin{array}{c}\text { Mainten } \\
\text {-ance }\end{array}$ & $\begin{array}{l}\text { Public } \\
\text { relations }\end{array}$ & $\begin{array}{c}\text { Expert } \\
\text { support }\end{array}$ & $\begin{array}{c}\text { Dedicated } \\
\text { support } \\
\text { organization }\end{array}$ & $\begin{array}{l}\text { Resident } \\
\text { participa } \\
\text {-tion }\end{array}$ & $\begin{array}{l}\text { Resident } \\
\text { participation } \\
\text { communica- } \\
\text { tion } \\
\text { methods }\end{array}$ \\
\hline \multirow{2}{*}{$\begin{array}{l}\text { Park et } \\
\text { al.(2010) }\end{array}$} & $\begin{array}{l}\text { Failure to provide legal support for } \\
\text { sanctions in violation of the agreement }\end{array}$ & & & $\mathrm{O}$ & & & & & & & \\
\hline & $\begin{array}{l}\text { The complexity and rigor of } \\
\text { administrative procedures }\end{array}$ & & & $\mathrm{O}$ & & & & & & & \\
\hline \multirow{5}{*}{$\begin{array}{c}\text { Kim et } \\
\text { al. }(2010)\end{array}$} & $\begin{array}{l}\text { The role of an expert in } \\
\text { understanding regional characteristics } \\
\text { in the guidance phase of the } \\
\text { landscape agreement and knowing } \\
\text { about the agreement }\end{array}$ & & & & & & & $\mathrm{O}$ & & & \\
\hline & $\begin{array}{l}\text { The role of experts for mainting the } \\
\text { participant relationship }\end{array}$ & & & & & & & $\mathrm{O}$ & & & \\
\hline & $\begin{array}{l}\text { Various communication methods for } \\
\text { inducing residents participation }\end{array}$ & & & & & & & & & & $\mathrm{O}$ \\
\hline & Residents' budget burden & & & & $\mathrm{O}$ & & & & & & \\
\hline & $\begin{array}{l}\text { Continuous management of } \\
\text { administrative and experts after } \\
\text { completion of the project }\end{array}$ & & & & & $\mathrm{O}$ & & & & & \\
\hline \multirow{2}{*}{$\underset{(2010)}{\operatorname{Kim}}$} & $\begin{array}{l}\text { Activeness and support of } \\
\text { administrative, representatives of } \\
\text { residents, and experts }\end{array}$ & & & & & & & & & $\mathrm{O}$ & \\
\hline & $\begin{array}{l}\text { Promote the media for the } \\
\text { improvement of resident participation }\end{array}$ & & & & & & $\mathrm{O}$ & & & & \\
\hline \multirow{3}{*}{$\begin{array}{c}\text { Ko et } \\
\text { al.(2016) }\end{array}$} & $\begin{array}{l}\text { Use of proper communication } \\
\text { techniques to enhance the capacity of } \\
\text { the residents }\end{array}$ & & & & & & & & & & $\mathrm{O}$ \\
\hline & $\begin{array}{l}\text { Adequate role of experts in the } \\
\text { process of agreement }\end{array}$ & & & & & & & $\mathrm{O}$ & & & \\
\hline & $\begin{array}{l}\text { Intermediate support organization or } \\
\text { pool of experts to enhance the } \\
\text { capacity of the residents }\end{array}$ & & & & & & & & $\mathrm{O}$ & & \\
\hline
\end{tabular}


(Table 3. Continued)

\begin{tabular}{|c|c|c|c|c|c|c|c|c|c|c|c|}
\hline \multirow{5}{*}{$\begin{array}{l}\text { Pyon } \\
(2010)\end{array}$} & $\begin{array}{l}\text { Enough explanation and education } \\
\text { about landscape agreement }\end{array}$ & $\mathrm{O}$ & & & & & & & & & \\
\hline & $\begin{array}{l}\text { Expert participation from the } \\
\text { pre-preparation stage }\end{array}$ & & & & & & & $\mathrm{O}$ & & & \\
\hline & Budget for expert support & & & & $\mathrm{O}$ & & & & & & \\
\hline & $\begin{array}{l}\text { Landscape agreement specialized } \\
\text { institution }\end{array}$ & & & & & & & & $\mathrm{O}$ & & \\
\hline & Incentives and sanctions & & & $\mathrm{O}$ & & & & & & & \\
\hline \multirow{5}{*}{$\begin{array}{l}\text { Lee et } \\
\text { al.(2011) }\end{array}$} & Maintenance after projects & & & & & $\mathrm{O}$ & & & & & \\
\hline & $\begin{array}{l}\text { Resident participation decision making } \\
\text { organization }\end{array}$ & & & & & & & & & & $\mathrm{O}$ \\
\hline & $\begin{array}{l}\text { Regulation and various incentive } \\
\text { measures in case of violation }\end{array}$ & & & $\mathrm{O}$ & & & & & & & \\
\hline & $\begin{array}{l}\text { Forming and supporting advisory } \\
\text { groups of experts and dispatched } \\
\text { officials }\end{array}$ & & & & & & & & $\mathrm{O}$ & & \\
\hline & $\begin{array}{l}\text { Assignment of landscape agreement } \\
\text { support manager to the landscape } \\
\text { department }\end{array}$ & & & & & & & & $\mathrm{O}$ & & \\
\hline \multirow{4}{*}{$\begin{array}{l}\text { Park et } \\
\text { al.(2015) }\end{array}$} & $\begin{array}{l}\text { Practical applicability, concrete and } \\
\text { circumstances }\end{array}$ & & $\mathrm{O}$ & & & & & & & & \\
\hline & $\begin{array}{l}\text { Cooperation with steering committee } \\
\text { and local governments }\end{array}$ & & & & & & & & & $\mathrm{O}$ & \\
\hline & $\begin{array}{l}\text { Priority propulsion of resident } \\
\text { awareness education }\end{array}$ & $\mathrm{O}$ & & & & & & & & & \\
\hline & $\begin{array}{l}\text { Continuous expert and participant } \\
\text { interest }\end{array}$ & & & & & & & & & $\mathrm{O}$ & \\
\hline \multirow[b]{2}{*}{$\begin{array}{l}\text { Lee } \\
(2016)\end{array}$} & $\begin{array}{l}\text { Sufficient public relations and } \\
\text { education for landscape agreements }\end{array}$ & $\mathrm{O}$ & & & & & & & & & \\
\hline & $\begin{array}{l}\text { Supporting to committees or public } \\
\text { space landscape improvement projects } \\
\text { that are willing to conclude landscape } \\
\text { agreements }\end{array}$ & $\mathrm{O}$ & & & & & & & & & \\
\hline \multirow{7}{*}{$\begin{array}{l}\text { Lee and } \\
\text { Shim } \\
(2017)\end{array}$} & $\begin{array}{l}\text { Conflicts caused by the inclusion of } \\
\text { public projects in the landscape } \\
\text { agreement }\end{array}$ & & $\mathrm{O}$ & & & & & & & & \\
\hline & $\begin{array}{l}\text { Lacks consensus formation between } \\
\text { resident because project is completed } \\
\text { within one year }\end{array}$ & $\mathrm{O}$ & & & & & & & & & \\
\hline & $\begin{array}{l}\text { Indifference and lack of management } \\
\text { after completion of public projects }\end{array}$ & & & & & $\mathrm{O}$ & & & & & \\
\hline & $\begin{array}{l}\text { Public relations of landscape } \\
\text { agreement system }\end{array}$ & & & & & & $\mathrm{O}$ & & & & \\
\hline & $\begin{array}{l}\text { Initial expenses and expert support to } \\
\text { prepare for the agreement }\end{array}$ & & & & $\mathrm{O}$ & & & & & & \\
\hline & Monitoring system & & & & & $\mathrm{O}$ & & & & & \\
\hline & Voluntary resources for residents & & & & $\mathrm{O}$ & & & & & & \\
\hline
\end{tabular}


Table 4. Sustainable operation seccess elements of landscape agreement

\begin{tabular}{|c|c|c|}
\hline Main category & Category & Details \\
\hline \multirow[t]{2}{*}{ Regional selection } & Resident awareness & $\begin{array}{l}\text { - Public domain support } \\
\text { - Resident awareness } \\
\text { - Recognizing the concept of landscape agreement and forming a consensus }\end{array}$ \\
\hline & Practical applicability & - Content that villagers can keep \\
\hline \multirow{4}{*}{ System } & Effectiveness of administrative means & $\begin{array}{l}\text { - Incentives } \\
\text { - Sanctions in case of violation } \\
\text { - Difficulties in administrative procedures }\end{array}$ \\
\hline & Securing budget & $\begin{array}{l}\text { - Residents' budget burden } \\
\text { - Voluntary resources for residents } \\
\text { - Budget for expert support and arrangements }\end{array}$ \\
\hline & Maintenance & $\begin{array}{l}\text { - Maintenance monitoring system } \\
\text { - Sustainable expert support system }\end{array}$ \\
\hline & Public relations & - Public relations of system \\
\hline \multirow{4}{*}{$\begin{array}{l}\text { Participant } \\
\text { group }\end{array}$} & Expert support & - Role of experts at each stage \\
\hline & Dedicated support organization & - Manager or organization dedicated to landscape agreements \\
\hline & Resident participation & - Active and sustainable support and cooperation \\
\hline & Resident participation communication methods & - Establishment of residents' consensus formation process \\
\hline
\end{tabular}

산, 사후 유지관리 모니터링 체계, 전문가 지속적 지원 근거, 제 도 홍보의 9 개 세부항목, 참여주체의 대분류에는 전문가 지원, 전담지원 조직, 참여의 지속성, 주민참여 의사소통방식의 4 개 중분류와 각 단계별 전문가의 역할, 경관협정 전담 인력 또는 기구 구성, 적극적이고 지속적인 지원 및 협조, 주민 주체적 합 의 형성 프로세스 정립의 4 개 세부항목으로 구성되었다(Table 4 참조).

\section{IV. 사례분석}

\section{1. 대상지 개요}

본 연구에서 사례로 하고 있는 대상지인 문갑도의 경우, 2009년 옹진군 섬 마을 리모델링 사업 공모에 선정되어 경관개 선 사업과 함께 경관협정을 체결하고, 아직까지 협정을 유지하 고 있는 사례이다(Table 5 참조). 사업 발굴 과정에서 행정 담 당자가 경관협정제도에 대해 알게 되면서 주민참여 및 사후 유 지관리를 위해 추진하게 되었다. 다양한 공동작업을 통해 이미
마을 공동체가 형성된 상황이었으며, 사업 공모 준비 시 마을 발전계획 수립을 위해 주민회의 및 토론 등으로 주민참여 의지 가 높았던 것이 이 마을의 특징이라 할 수 있다. 이 마을특성에 맞는 경관사업 및 경관협정제도 적용을 위해 사업 초기단계부 터 주민설명회를 20회 이상 추진, 전문가와 행정 담당자로 구 성된 도시디자인추진단 및 사업 총괄 $\mathrm{MP}$ 의 6 차례 이상 현장 답사와 회의 추진으로 약 1 년 2 개월만에 경관협정을 체결하게 되었다.

수원 거북시장길의 경우, 경관협정 국내 선도사례를 만들고 자 전문가들의 논의가 있던 가운데, 상권이동 및 문화재보호구 역 지정으로 점차 쇠퇴하고 있는 전통시장 활성화를 위해 전문 가들의 주민 설득에서 시작된 사례이다(Table 6 참조). 처음에 경관협정제도의 취지와 필요성을 이해하지 못했던 상인과 주 민들에게 제도에 대한 이해 및 공감대 형성을 위해 전문가들은 교육, 워크숍, 세미나, 국내외 선진사례 견학 등 다양한 방법으 로 지원을 했다. 이러한 지속적인 지원과 주민들의 참여 과정 결 과, 약 3 년 반 만에 경관협정을 체결하여 현재까지 유지하고 있 는 사례이다.

Table 5. Background and process of landscape agreement of Ongjin-gun Mungab Island

\begin{tabular}{c|l}
\hline $\begin{array}{c}\text { Progress } \\
\text { background }\end{array}$ & $\begin{array}{l}\text { - Selected as "Mungapdo Island Total Design Village Project" in March } 2010 . \\
\text { - Signed a landscape agreement in May 2011. }\end{array}$ \\
\hline \multirow{2}{*}{ Site character } & $\begin{array}{l}\text { - Mungab-ri, Deokjeok-myeon, Ongjin-gun, Incheon, Island located on the west side of Ongjin-gun } \\
\text { - Promote of the residents meeting and discussion. }\end{array}$ \\
\hline \multirow{2}{*}{$\begin{array}{c}\text { Progress } \\
\text { process }\end{array}$} & $\begin{array}{l}\text { - Promotion of landscape projects and landscape agreements in } 2009 \text { with the recommendation of the administrator } \\
\text { - After selecting a project site, a landscape agreement will be concluded approximately one year and two months after the project was } \\
\text { promoted through } 20 \text { information sessions for residents and field meetings by experts. }\end{array}$ \\
\hline
\end{tabular}


Table 6. Background and process of landscape agreement of Suwon Cobuk Market

\begin{tabular}{c|l}
\hline $\begin{array}{c}\text { Progress } \\
\text { background }\end{array}$ & - Starting with the persuasion of merchants and residents by experts \\
\hline \multirow{5}{*}{ Site character } & - A historical market formed in 1797 with Suwon Hwaseong \\
- Suwon's representative market until the early 1990s, where there was a bus terminal to Seoul \\
- Decline since the 1990s, leaving only restaurants and lodgings \\
- As Suwon Hwaseong is listed as a World Cultural Heritage, it is designated as a cultural property protection zone, and the region's vitality \\
is gradually lost due to the development activity regulation
\end{tabular}

\section{2. 대상지 선정}

\section{1) 주민의지}

섬마을의 특징을 가지고 있는 문갑도의 경우, 어구적재, 산책 로 등을 협정내용으로 하고 있으며, 상가를 대상으로 하는 거 북시장길의 경우 상가 외관 및 간판 개선 등 사적 영역이지만 공공성을 가지고 있는 대상을 내용으로 하고 있다. 또한 문갑 도의 경우, 경관사업 공모 선정 기준에서 주민의지가 높은 곳 으로서, 경관협정 체결 전부터 경관관리에 대한 주민의지가 높 은 곳이었던 반면, 거북시장길의 경우 경관관리에 대한 주민 의지가 상대적으로 적은 편이었다. 문갑도는 약 1년 2개월, 거북시장길은 약 3 년 반이라는 기간의 경관협정 체결 준비기 간이 있었다. 이 기간동안 경관협정의 개념, 주민역할 등 충 분한 사전 설명회 또는 교육, 워크숍 등을 통해 주민들이 경 관협정에 자발적으로 참여하고 공감대를 형성할 수 있도록 충분한 사전준비가 있었다. 거북시장길의 경우, 준비기간동 안 경관협정에 대한 주민의지가 향상되었다고 할 수 있다 (Table 7 참조).

\section{2) 실현 가능성}

경관협정서 내용을 보면 문갑도의 경우 섬 마을이면서 관광 지의 특성을 반영하여 쓰레기, 어구적재, 외부인 관리, 마을의 정체성을 나타내는 경관보존 내용까지 포함하고 있다. 즉, 공적 영역과 사적 영역의 내용을 모두 담고 있으며, 디자인 행위에 대한 규제보다는 대부분 경관관리 및 경관활동 등 주민들이 관 심을 가지면 쉽게 할 수 있는 내용으로 구성되어 있다. 한편, 거북시장길의 경우, 건축물 및 공작물에 대한 디자인 행위는 물론, 불법광고물 및 가판대 설치 금지, 건강한 먹거리와 음식 점의 청결 등 상업지구의 특징을 반영하면서 역시 공적 영역과 사적 영역의 내용을 담고 있다. 문갑도와 달리 상업지역의 특 성상 디자인 행위 규제를 통한 경관관리가 소득향상에 영향을 준다고 인식하고 있어 경관협정 내용에 이를 반영하고 있음을 알 수 있다(Table 7 참조).

\section{3. 제도}

1) 행정수단의 실효성

문갑도의 경우, 경관조례에 우수한 사례에 대한 표지부착 및 표창, 포상금 지급 등 인센티브를 명시하여 경관협정이 활성화 될 수 있도록 하고 있는 반면, 거북시장길의 경우 이에 대한 규 정은 없다. 또한 협정내용 위반 시 제재조치로서, 문갑도는 공 공근로 등에 참여 제한을 경관협정서에 명시하고 있으며, 거북 시장길은 경관협정운영회 및 행정, 전문가 등이 해당 행위를 판단하여 보조금 및 사업비를 환수하도록 경관협정서에 명시 하고 있다. 하지만 위력을 가하지는 못하는 상황이다.

경관협정은 해당 지자체의 경관위원회 심의, 경관협정서 작 성 및 경관협정운영회 설립 등 주민 스스로 하기에 행정절차상 어려움이 있다는 문제는 지속적으로 제기되어 왔다. 두 사례 모두 경관협정 체결 준비단계부터 유지관리단계까지 경관협정 에 관심을 가지고 있는 담당자가 있어 행정지원이 안정적으로 이루어질 수 있었다. 특히, 거북시장길의 경우, 경관조례에 행 정 및 재정지원 규정, 경관협정서에는 전문가로 구성된 어드바 이저가 경관협정 체결 및 운영 조언을 할 수 있도록 명시하고 있다. 이는 인가절차를 위한 심의의 행정절차 어려움 해소는 물론, 경관협정의 효과를 높이기 위한 사업 및 협정 운영 전반 에 걸친 지원의 근거를 마련해 놓고 있는 것이라 볼 수 있다 (Table 7 참조).

\section{2) 예산 확보}

두 사례 모두 사적 영역에 사업비가 투입될 경우, 주민 자부 담 $20 \%$ 를 하도록 경관협정서에 명시하고 있다. 하지만 거북시 장길의 경우 사적 영역의 사업은 체결자가 부담하는 것이 기본 원칙이며, 필요 시 행정이 지원하도록 하여 경관협정 체결과 운영 주체는 주민이라는 것을 부각시키고 있다.

경관협정의 지속적 운영을 위해서는 수반되는 예산 역시 필 요한데, 거북시장길의 경우 경관협정에 필요한 운영비를 회비 나 찬조금, 보조금으로 충당하도록 협정서에 명시하여 주민의 
Table 7. Progress status of cases by sustainability operation success elements of landscape agreement

\begin{tabular}{|c|c|c|c|c|c|}
\hline $\begin{array}{c}\text { Main } \\
\text { category }\end{array}$ & Category & & Details & $\begin{array}{c}\text { Ongïn-gun Mungap } \\
\text { Island }\end{array}$ & $\begin{array}{c}\text { Suwon Gobuk } \\
\text { Market }\end{array}$ \\
\hline \multirow{4}{*}{$\begin{array}{l}\text { Regional } \\
\text { selection }\end{array}$} & \multirow{3}{*}{ Resident awareness } & \multicolumn{2}{|l|}{ Public domain support } & $\mathrm{O}$ & $\mathrm{O}$ \\
\hline & & \multicolumn{2}{|l|}{ Resident awareness } & $\mathrm{O}$ & $x$ \\
\hline & & \multicolumn{2}{|c|}{ Recognizing the concept of landscape agreement and forming a consensus } & O & O \\
\hline & Practical applicability & \multicolumn{2}{|l|}{ Content that villager can keep } & $\mathrm{O}$ & $\mathrm{O}$ \\
\hline \multirow{12}{*}{ System } & \multirow{4}{*}{$\begin{array}{c}\text { Effectiveness of } \\
\text { administrative means }\end{array}$} & \multicolumn{2}{|l|}{ Incentive } & $\mathrm{O}$ & $x$ \\
\hline & & \multicolumn{2}{|l|}{ Sanctions in case of violation } & $\mathrm{O}$ & O \\
\hline & & \multirow{2}{*}{$\begin{array}{l}\text { Difficulties in administrative } \\
\text { procedures }\end{array}$} & Manager same & $\mathrm{O}$ & $\mathrm{O}$ \\
\hline & & & $\begin{array}{l}\text { Express of support regulations in ordinance } \\
\text { and agreements }\end{array}$ & $x$ & $\mathrm{O}$ \\
\hline & \multirow{5}{*}{ Budget securing } & \multicolumn{2}{|l|}{ Residents' budget burden } & $\mathrm{O}$ & $\mathrm{O}$ \\
\hline & & \multicolumn{2}{|l|}{ Voluntary resources for residents } & $x$ & $\mathrm{O}$ \\
\hline & & \multirow{3}{*}{$\begin{array}{l}\text { Budget for expert support and } \\
\text { arrangements }\end{array}$} & Support to national project & $\mathrm{O}$ & $\mathrm{O}$ \\
\hline & & & Local government support & $\mathrm{O}$ & $\mathrm{O}$ \\
\hline & & & Determined by agreement & $x$ & $\mathrm{O}$ \\
\hline & \multirow{2}{*}{ Maintenance } & \multicolumn{2}{|l|}{ Maintenance monitoring system } & $\mathrm{O}$ & $\mathrm{O}$ \\
\hline & & \multicolumn{2}{|l|}{ Sustainable expert support system } & $\mathrm{O}$ & $\mathrm{O}$ \\
\hline & Public relations & \multicolumn{2}{|l|}{ Public relations of system } & $x$ & $\mathrm{O}$ \\
\hline \multirow{9}{*}{$\begin{array}{l}\text { Participant } \\
\text { group }\end{array}$} & \multirow{3}{*}{ Expert support } & \multirow{3}{*}{ Role of experts at each stage } & $\begin{array}{l}\text { Information sessions, education, workshops, } \\
\text { etc. }\end{array}$ & $\mathrm{O}$ & $\mathrm{O}$ \\
\hline & & & $\begin{array}{l}\text { Making landscape agreements, planning, } \\
\text { etc. }\end{array}$ & $\mathrm{O}$ & $\mathrm{O}$ \\
\hline & & & $\begin{array}{l}\text { Review and advise on the appropriateness } \\
\text { of conduct }\end{array}$ & $\mathrm{O}$ & $\mathrm{O}$ \\
\hline & \multirow{2}{*}{$\begin{array}{l}\text { Dedicated support } \\
\text { organization }\end{array}$} & \multirow{2}{*}{$\begin{array}{l}\text { Manager or organization } \\
\text { dedicated to landscape } \\
\text { agreements }\end{array}$} & Specialty organization & $x$ & $\triangle$ \\
\hline & & & Specialty official & $\mathrm{O}$ & $\mathrm{O}$ \\
\hline & \multirow{2}{*}{ Resident participation } & \multirow{2}{*}{$\begin{array}{l}\text { Active and sustainable } \\
\text { support and cooperation }\end{array}$} & Constant attention of administration & $\mathrm{O}$ & $\mathrm{O}$ \\
\hline & & & Compliance with the agreement & $\mathrm{O}$ & $\mathrm{O}$ \\
\hline & \multirow{2}{*}{$\begin{array}{l}\text { Resident participation } \\
\text { communication methods }\end{array}$} & \multirow{2}{*}{$\begin{array}{l}\text { Establishment of residents } \\
\text { consensus formation process }\end{array}$} & Regular residents' meetings & $\mathrm{O}$ & $\mathrm{O}$ \\
\hline & & & $\begin{array}{l}\text { Various techniques such as education, } \\
\text { workshops and seminars }\end{array}$ & $\triangle$ & $\mathrm{O}$ \\
\hline
\end{tabular}

자발적 재원 조성 장치를 마련하고 있다.

문갑도의 경우, 전문가 지원 및 협정준비를 위한 예산 지원 의 제도적 근거는 별도 마련해 놓고 있지 않다. 하지만 2014년 경관헙정지원 시범사업 및 2015년 민간전문가 활용 지원사업 등 국토부 사업과 연계하여 전문가를 지원하였고, 현재 옹진군 자체 예산을 확보하여 외부전문가 지원을 지속적으로 유지하 고 있다. 한편, 거북시장길의 경우 경관협정 체결 준비과정에서 2012년 국토부 도시활력증진사업에 선정되었으며, 경관협정 체 결을 준비한지 약 1 년 이후에 전문가 자문비 및 회의운영비 등 의 협정지원비 2 천만원을 수원시가 지원하는 등 경관협정 체결 준비 및 사업 예산을 확보하고 있음을 알 수 있다. 또한 경관협 정서에는 협정체결 초기부터 지원했던 전문가들이 필요 시 지
원, 그리고 각 분야 전문가들로 구성된 기술자문단 구성까지 명시해 놓고 있다. 그리고 경관협정운영회가 경관협정사업의 원활한 추진을 위해 행정조직 및 전문연구조직 등과 협력체계 를 구성할 수 있으며, 협력기구로부터 기술적 - 재정적 - 행정적 지원과 조언을 받을 수 있도록 명시하고 있다. 필요한 경우 예 산 범위내에서 자문비, 출장비, 기술비용, 재료비 등의 일부를 지급할 수 있도록 명시함으로써 지원 주체에 대한 예산을 제도 적으로 마련하고 있다(Table 7 참조).

3) 유지관리

문갑도는 경관조례에 경관협정에 대한 평가와 결과를 정책 에 반영하도록 규정하고 있으며, 거북시장길의 경우 경관협정서 
에 협정 체결자가 협정 내용을 준수할 수 있도록 경관협정운영 회, 자문위원회, 어드바이저의 지원을 구체적으로 명시하고 있 다. 또한 경관협정 체결 내용이 지속적으로 운영될 수 있도 록 전문가 역시 지속적으로 지원할 수 있도록 문갑도는 경 관조례에, 거북시장길은 경관협정서에 명시하고 있다(Table 7 참조).

\section{4) 홍보}

문갑도는 특별히 홍보활동을 하지는 않았지만 2011년 제1회 대한민국 경관대상 농산어촌분야 최우수상 수상, 2015년 제12 회 대한민국 지방자치경영대전 지역개발부분 최우수상 수상은 물론, 도서지역 중 경관협정을 최초로 체결한 사례로 유명세를 타며 우리나라에서 경관협정 선도사례로 꼽히고 있다. 또한 경 관협정을 체결하여 마을이 깨끗해지는 것을 직접 알게 된 주변 의 8개 섬마을에서 경관협정을 체결 운영하는 등 주변지역에까 지 파급이 되고 있다.

한편, 거북시장길의 경우 경관협정 준비 과정에서 주민들이 소식지를 발행하거나, 수원시가 경관협정 홍보 팸플릿을 발간 하여 공무원 및 주민들에게 제도를 홍보하고 있다. 또한 협정 체결 절차 및 방법 등 매뉴얼을 발간하여 경관협정 체결 시 활 용하도록 하고 있다. 현재 수원시에서는 거북시장길과 성대 밤 밭 거리에서 경관협정을 운영하고 있으며, 이 외에 두 곳에서 경관협정 체결을 준비하고 있다. 특히, 거북시장길은 경관협정 서에 협정 내용을 준수할 수 있도록 홍보와 지도를 명시하고 있다(Table 7 참조).

\section{4. 참여주체}

\section{1) 전문가 지원}

문갑도의 경우, 경관협정이 사업과 연계되어 추진되면서 협 정 체결 준비단계에서는 $\mathrm{MP}$ 제도, 체결단계에서는 사업 계획 수립 등 전문가 지원이 있었으며, 운영 및 관리단계에서는 국 비 공모사업에 선정되면서 전문가 지원, 현재는 군비로 지속적 으로 지원하고 있다.

한편, 경관관리에 대한 주민참여 공감대가 형성된 상황에서 경관협정을 추진했던 문갑도와 달리, 거북시장길은 주민참여 경관개선 공감대 형성을 위해 약 3 년 반이라는 기간동안 꾸준 한 전문가의 지원이 큰 역할을 했다. 협정 체결 준비단계에서 교육, 워크솝, 현장답사 등 월 2회 정기적인 모임을 갖고, 충분 한 기간동안 공감대를 형성할 수 있도록 지원이 있었다. 경관 협정 체결단계에서는 국비 공모사업에 당선됨에 따라 사업계 획 수립 및 경관협정서 작성 등의 지원이 있었고, 운영 및 관리 단계에서는 협정구역안에서의 행위 적정성 검토와 자문 등 단 계별로 적절한 전문가의 지원이 있었다(Table 7 참조).

\section{2) 전담지원 조직}

경관협정 추진을 위한 전담조직은 문갑도의 경우 없으며, 거 북시장길은 전담조직은 아니지만 경관협정 체결을 유도한 전 문가(어드바이저), 그리고 각 분야 전문가 및 시민단체로 구성 된 기술자문단이 경관협정을 원활히 유지하도록 경관협정서에 지원 역할을 명시하고 있다. 구체적으로 어드바이저는 지역 활 성화와 연구 지원, 협정에 관한 운영 및 관리 자문의 역할, 기 술자문단은 경관협정사업 및 관리에 대한 기술적 지원과 모니 터링의 역할을 하도록 하고 있다.

경관협정은 행정조직체계에서 업무분장에 없는 지자체가 많 은 것이 현실이나, 두 사례 모두 경관협정 전담조직은 아니지 만 경관협정을 전담하는 공무원이 있어 타 지자체보다 경관협 정을 추진할 수 있는 여건이 나음을 알 수 있다(Table 7 참조).

\section{3) 참여의 지속성}

두 사례 모두 협정체결 초기부터 업무를 담당했던 공무원이 지 속적으로 지원해 왔으며, 특히 경관협정 효과 향상 및 운영을 위 해 국비 공모사업 추진 등의 역할을 해왔다. 지금까지도 경관협정 의 유지를 위해 주민과의 빈번하고 긴밀한 논의를 지속하고 있다. 물론 주민들 역시 대표를 중심으로 적극적으로 경관관리 및 경관활동 등 경관협정 체결 시 합의에 의해 만들어진 협정서 내용을 준수하고 있다. 문갑도의 경우, 마을축제 및 마을기업 운영, 해안도로 화단 조성, 마을 화단조성, 폐가 철거 등 협정내 용을 꾸준히 준수하고 있으며, 거북시장길의 경우에도 정기적 으로 거리 및 건축물 청소 가판대 설치 금치 및 불법광고물 금 지, 쓰레기 적치 금지 등의 활동을 하고 있다.

지금까지 경관협정을 체결한 사례가 약 40 곳에 해당되나, 그 중에서도 이 두 곳이 선진사례로 꼽히는 이유는 행정 담당자의 지속적인 관심과 지원, 그리고 주민의 적극적인 참여가 있었기 에 가능한 것이라 할 수 있다(Table 7 참조).

\section{4) 주민참여 의사소통방식}

두 사례 모두 경관협정 체결 이전부터 주민들 간 의사소통은 원활한 편이라 볼 수 있다. 거북시장길은 시장 활성화에 대한 의지가 있어 상인회 모임은 있었으나, 경관관리의 관심과 의지 가 조금 부족했다. 이에, 경관협정 체결 준비기간 동안에 교육, 워크숍, 세미나 등 다양한 의사소통방식을 통해 경관관리를 위 해 주민들이 결정하고 활동할 수 있는 기반을 마련하였다.

문갑도의 경우, 작은 섬마을이라는 지역적 특성도 있어 마을 회의 또는 마을공동작업 경험이 많아, 이미 주민들 간 의사결 정 논의기구가 구축되어 있었다고 볼 수 있다. 도시지역에 비 해 지가상승에 대한 부담이 상대적으로 적은 섬마을의 지리적 특성도 있지만, 이러한 의사결정 논의에 익숙하고 경관개선에 대한 의지 또한 있었기에, 주민설명회 20회 정도로 경관협정 
체결이 가능하였다고 볼 수 있다(Table 7 참조).

\section{5. 소결}

경관협정 지속적 운영 성공요소(안)을 두 곳 선진사례에 적 용해봄으로써, 경관협정이 주민참여를 전제로 하는 제도이기는 하나, 각 요소에 따른 참여주체, 즉 주민을 비롯하여 전문가, 행 정의 역할 역시 중요함을 알 수 있었다. 또한 경관협정의 세부 적인 사항을 지역의 특성에 맞게 지자체의 조례 및 경관협정서 에 규정하여 근거를 확보하고 있음을 알 수 있었다. 그리고 사 례분석을 통해 앞에서 제시한 경관협정 지속적 운영 성공요소 (안)을 더욱 구체적으로 3 개의 대분류와 10 개의 중분류, 25 개 의 세부항목의 최종안을 제시할 수 있었으며, 운영요소에 따른 경관협정 단계별 참여주체의 역할과 이를 근거할 수 있는 수단 도 제시할 수 있었다(Table 7 참조).

\section{V. 경관협정 지속적 운영 성공요소별 추진방향}

\section{1. 대상지 선정}

경관협정 체결 대상지는 무엇보다 경관관리에 대한 주민의 지가 높으며, 경관협정에 대한 이해와 공감대가 형성된 곳을 선정하도록 한다. 거북시장길의 경우와 같이 경관관리 주민의
지가 높지 않은 경우, 전문가 지원으로 사전에 충분한 교육 및 설명회 등 경관협정 개념 인식과 공감대가 형성된 이후, 협정 체결을 할 수 있도록 한다. 또한 주민들 간 공감대가 형성되어 경관협정 체결 시에는 주민 스스로 꾸준히 지킬 수 있는 내용 중심으로 협정서를 작성할 수 있도록 주민들 간 충분한 합의형 성이 필요하다(Table 8 참조)

\section{2. 제도}

행정수단의 실효성 측면에서 경관협정 준비단계부터 경관협 정 체결 인가 및 사후 유지관리 등 안정적으로 운영될 수 있도 록 행정 담당 업무를 조례에서 규정하고, 전문가 역시 단계별 로 지원할 수 있도록 조례 규정이 필요하다. 또한 경관협정 홍 보와 활성화를 위한 인센티브는 행정 담당자의 사기진작에 기 여할 수 있으므로 조례에서 규정하도록 하며, 경관협정 체결 후 협정내용 위반 시 제재조치는 경관협정제도의 취지 상 법적 규제를 적용할 수는 없으므로, 사전에 주민들이 지킬 수 있으 면서 꼭 필요한 사항 중심으로 체결할 수 있도록 협정서를 작 성하도록 유도한다.

두 사례에서 보았듯이 경관협정 체결을 위한 준비단계, 체결 단계, 체결 이후 단계에서 주민 대상 교육 및 워크숍, 경관협정 서 작성 등에 필요한 활동비 및 자문비의 예산이 소요된다. 이 에, 경관협정 체결 준비단계부터 체결단계까지 경관협정 체결

Table 8. Sustainable operational success elements and progress directions of the landscape agreement

\begin{tabular}{|c|c|c|c|c|c|c|c|c|c|c|}
\hline \multirow{2}{*}{$\begin{array}{l}\text { Main } \\
\text { category }\end{array}$} & \multirow{2}{*}{ Category } & \multirow{2}{*}{ Details } & \multicolumn{3}{|c|}{ Participant } & \multicolumn{2}{|c|}{ Method } & \multicolumn{3}{|c|}{ Landscape agreement phase } \\
\hline & & & Administration & Expert & Residents & Ordinance & Agreement & Preparations & Signing & Maintenance \\
\hline \multirow{4}{*}{$\begin{array}{l}\text { Regional } \\
\text { selection }\end{array}$} & \multirow{3}{*}{$\begin{array}{l}\text { Resident } \\
\text { awareness }\end{array}$} & Public domain support & (0) & () & & & & $---->>$ & & \\
\hline & & Resident awareness & () & (C) & & & & $---->>$ & & \\
\hline & & $\begin{array}{l}\text { Recognizing the concept of landscape } \\
\text { agreement and forming a consensus }\end{array}$ & & (C) & & & & $---->>$ & & \\
\hline & \begin{tabular}{|c|} 
Practical \\
applicability
\end{tabular} & Content that villager can keep & & (C) & (C) & & $\mathrm{O}$ & |------- & $\rightarrow>$ & \\
\hline \multirow{12}{*}{ System } & \multirow{4}{*}{$\begin{array}{l}\text { Effectiveness } \\
\text { of } \\
\text { administrative } \\
\text { means }\end{array}$} & Incentive & () & & & $\mathrm{O}$ & & & & $---->>$ \\
\hline & & Sanctions in case of violation & (2) & (C) & & & $\mathrm{O}$ & & & $---->>$ \\
\hline & & Manager same & (2) & & & $\mathrm{O}$ & & --------- & ----- & $----->$ \\
\hline & & $\begin{array}{l}\text { Express of support regulations in } \\
\text { bylaws and agreements }\end{array}$ & () & (9) & & $\mathrm{O}$ & & --- & ------ & $---->$ \\
\hline & \multirow{5}{*}{$\begin{array}{l}\text { Budget } \\
\text { securing }\end{array}$} & Residents' budget burden & & & (2) & & $\mathrm{O}$ & & & $---->>$ \\
\hline & & Voluntary resources for residents & & & () & & 0 & & & $---->>$ \\
\hline & & Support to national project & () & & & & & & ----- & $---->>$ \\
\hline & & Local government support & () & & & $\mathrm{O}$ & $\mathrm{O}$ & ---------- & $-\rightarrow>$ & \\
\hline & & Determined by agreement & () & & (2) & & $\mathrm{O}$ & & ----- & $---->>$ \\
\hline & \multirow{2}{*}{ Maintenance } & Maintenance monitoring system & & (2) & & $\mathrm{O}$ & $\mathrm{O}$ & & & $---->>$ \\
\hline & & Sustainable expert support system & & (2) & & $\mathrm{O}$ & $\mathrm{O}$ & & & $---->>$ \\
\hline & $\begin{array}{l}\text { Public } \\
\text { relations }\end{array}$ & Public relations of system & () & & & & & -- & ----- & $--->$ \\
\hline
\end{tabular}


(Table 8. Continued)

\begin{tabular}{|c|c|c|c|c|c|c|c|c|c|c|}
\hline \multirow{2}{*}{$\begin{array}{l}\text { Main } \\
\text { category }\end{array}$} & \multirow{2}{*}{ Category } & \multirow{2}{*}{ Details } & \multicolumn{3}{|c|}{ Participant } & \multicolumn{2}{|c|}{ Method } & \multicolumn{3}{|c|}{ Landscape agreement phase } \\
\hline & & & Administration & Expert & Residents & Ordinance & Agreement & Preparations & Signing & Maintenance \\
\hline \multirow{9}{*}{$\begin{array}{l}\text { Participant } \\
\text { group }\end{array}$} & \multirow{3}{*}{$\begin{array}{l}\text { Expert } \\
\text { support }\end{array}$} & $\begin{array}{l}\text { Information sessions, education, } \\
\text { workshops, etc. }\end{array}$ & & (2) & & $\mathrm{O}$ & & $---->>$ & & \\
\hline & & $\begin{array}{l}\text { Making landscape agreements, } \\
\text { planning, etc. }\end{array}$ & & (a) & & $\mathrm{O}$ & & & $\rightarrow>$ & \\
\hline & & $\begin{array}{l}\text { Review and advise on the } \\
\text { appropriateness of conduct }\end{array}$ & & () & & & $\mathrm{O}$ & & & $\mid---->>$ \\
\hline & \multirow{2}{*}{$\begin{array}{c}\text { Dedicated } \\
\text { support } \\
\text { organization }\end{array}$} & Specialty organization & (a) & (a) & & & & |---------- & ------ & $----->>$ \\
\hline & & Specialty official & (0) & & & $\mathrm{O}$ & & |-------- & ----- & $---->>$ \\
\hline & \multirow{2}{*}{$\begin{array}{c}\text { Resident } \\
\text { participation }\end{array}$} & Constant attention of administration & (2) & & & $\mathrm{O}$ & & |--------- & ----- & $---->>$ \\
\hline & & Compliance with the agreement & & & () & & $\mathrm{O}$ & & ----- & $----->$ \\
\hline & \multirow{2}{*}{$\begin{array}{c}\text { Resident } \\
\text { participation } \\
\text { communication } \\
\text { methods }\end{array}$} & Regular residents meetings & & & (2) & & $\mathrm{O}$ & |-------- & ----- & $\mid---->>$ \\
\hline & & $\begin{array}{l}\text { Various techniques such as education, } \\
\text { workshops and seminars }\end{array}$ & & () & () & & $\mathrm{O}$ & & ----- & -----> \\
\hline
\end{tabular}

을 위한 지자체의 경비 지원을 조례에 규정하고, 체결 이후에 전문가 자문비 등 소요되는 예산은 체결자들의 회비 및 보조금 등으로 충당할 수 있도록 협정서에 명시하여 주민의 자발적 재 원으로 운영하도록 유도한다. 또한 경관협정의 효과 향상 및 유지관리를 위해 행정이 국비사업에 공모하는 등의 노력이 필 요하며, 사업추진 시 사적영역에 대해서는 주민이 자부담을 할 수 있도록 협정서에 명시가 필요하다.

경관협정은 유지관리가 매우 중요하다. 주민들이 협정체결 시 작성한 협정서대로 이행하고 있는지 여부를 전문가가 모니 터링 및 평가할 수 있도록 조례에 규정하고, 또한 협정서에 전 문가와 주민의 역할을 명시하도록 한다. 이와 더불어, 거북시장 길과 같이 경관협정 매뉴얼 개발 및 소식지 발간 등 제도의 홍 보를 위한 행정의 적극적인 관심이 필요하다(Table 8 참조).

\section{3. 참여 주체}

두 선진사례에서 알 수 있듯이 경관협정은 주민과 전문가, 행 정이 상호 협력해야 체결이 가능하며 지속성 또한 확보할 수 있 다. 이에, 전문가가 준비단계부터 체결단계까지 경관협정 체결을 위한 주민 교육 및 경관협정서 작성 등 다양한 방식과 내용의 지원이 가능하도록 조례에서 규정하고, 협정 체결 이후 유지관 리 단계에서는 필요 시 지원할 수 있도록 협정서에서 명시한다.

두 사례에는 경관협정을 전담으로 하는 지원조직은 없으나, 지속적인 전문가의 지원과 경관협정 업무를 담당하는 공무원 이 있었기에 현재까지 유지되고 있는 것이다. 경관협정 활성화 를 위해서는 최소한 경관협정에 관심을 가지고 업무에 임할 수 있도록 인력 배치에 대한 조례 규정이 필요하다. 물론 두 선진 사례에서의 담당 공무원은 임기제공무원은 아니나, 공무원의
순환보직이라는 특징에 따른 업무의 연속성과 전문성 확보의 한계를 보완하기 위해, 경관협정에 대한 전문지식을 갖춘 임기 제공무원 활용방안 마련, 더불어 5년 한시적 임기에 따른 업무 지속성 확보 한계 역시 보완이 필요하다.

주민참여 의사소통방식은 경관협정을 유지하게 하면서 동시 에 주민들 간 주체적 합의형성 프로세스를 확립하게 하는 과정 으로도 볼 수 있다. 정기적인 회의를 통해 주민들 간 교류증진 은 물론, 교육 및 워크숍 등을 통해 경관협정을 활성화하는데 주민들 간 의사결정이 가능하도록 협정서에 명시가 필요하다 (Table 8 참조).

\section{V. 결론}

본 연구에서는 경관관리에 있어서 주민의 역할이 점차 중요 해지고 있는 가운데, 경관협정의 지속적 운영을 위한 성공요소 와 이를 위한 추진방향을 제시하였으며, 그 성과는 다음과 같다.

첫째, 3 개의 대분류와 10 개의 중분류, 25 개의 세부항목으로 구성된 경관협정 지속적 운영의 성공요소를 제시하였다. 이는 주민의지, 실현가능성, 행정수단의 실효성, 예산확보, 유지관리, 홍보, 전문가 지원, 전담지원 조직, 참여의 지속성, 주민참여 의 사소통방식에 대하여 경관협정 체결 준비단계부터 체결단계, 유지관리단계에서 전반적으로 고려해야 하면서도 구체적인 세 부항목으로 구성되어 있다. 이것은 지금까지 진행된 선행연구 에서 경관협정 운영의 과제 및 문제점을 단편적으로 제시한 것 과는 차별화되는 것으로써, 경관협정을 체결하고자 하는 지자 체에서 단계별로 적용하는데 도움을 줄 수 있을 것이다.

둘째, 우리나라에서 선진사례로 꼽히는 두 곳 사례분석을 통 
해 경관협정 지속적 운영의 성공요소에 따른 추진방향을 제시 하였다. 경관협정 체결은 주민의지가 높으며, 경관협정에 대한 공감대가 형성된 이후에 주민들이 스스로 지킬 수 있는 내용 중심으로 협정을 체결할 필요가 있다. 또한 행정절차의 복잡함 과 유지관리가 중요한 경관협정제도의 특성상 행정 담당자가 지속적으로 업무할 수 있도록 제도적 기반 마련과 함께, 경관 협정 체결준비부터 유지관리단계에 소요되는 자문비 및 활동 비의 예산확보 근거 마련 역시 필요하다 할 수 있다. 그리고 경 관협정 체결자인 주민들 간 지속적인 교류 및 역량강화를 위한 노력, 이를 위한 전문가의 주민참여 역량 정도에 맞는 단계별 지원, 이를 근거할 수 있는 제도 마련 역시 필요하다 할 수 있다. 셋째, 주민참여의 경험과 기반이 충분하지 않아 아직까지 행 정의 지원에 익숙해져 있는 우리나라의 현재 여건에서 본다면 관 또는 전문가가 주도하여 주민참여를 유도하는 것도 경관협 정제도를 활성화시키는데 도움이 될 수 있다는 것을 알 수 있 다. 경관협정을 공공사업과 연계하여 추진하는 것 자체보다 경 관협정을 공공사업 예산 확보를 위한 수단으로만 이용하는 것 에 문제의식을 가질 필요가 있다. 문갑도 사례와 같이 공공사 업과 연계하여 경관협정을 추진하더라도 주민참여 역량정도에 맞는 행정 및 전문가의 지원, 그리고 경관협정에 대한 이해와 공감대를 형성할 수 있는 충분한 노력이 전제된다면 경관협정 은 지속적으로 운영될 수 있다. 즉, 경관협정을 공공사업과 연 계 추진하더라도 주민참여 역량이 갖추어져 있는 곳 대상 지원 여부, 또는 주민참여 경관관리가 가능하도록 행정 및 전문가의 지속적인 관심과 지원 여부가 경관협정의 지속적 운영에 중요 한 영향을 미칠 수 있다고 볼 수 있다.

본 연구는 경관협정 관련 선행연구에서 문제점 및 과제를 도 출하여 경관협정의 지속적 운영의 성공요소를 제시한 후, 두 곳의 선진사례에 적용함으로써 성공요소별 추진방향을 제시하 였다. 물론 성공하지 못한 사례에 대한 분석 또한 포함할 필요 가 있으나, 담당자가 바뀌어 내용 파악이 어렵거나 조사를 꺼 려하여 포함하지 못한 점, 그리고 두 곳이라는 제한된 사례를 적용하여 일반화시키기에 어려울 수 있다는 한계점을 가지고 있다. 하지만 두 사례의 서로 다른 방식과 내용의 경관협정을 지속적으로 유지할 수 있었던 방법을 확인하는데 의의가 있으 며, 향후, 성공하지 못한 사례를 포함한 다양한 사례의 분석을 통해 경관협정의 지속적 운영을 위한 성공요소와 이에 따른 추 진방향에 대하여 보다 더 심층적인 방안을 제시하고자 한다.

주 1. Lee and Shim(2017)가 조사한 자료에 의하면, 2016년 조사 당시 집
계된 총 28 곳 중 유효기간이 종료된 곳 6 곳을 제외한 22 곳 중 실질적 으로 운영되고 있는 대상지는 7곳에 불과하며, 지역주민 및 해당 지 자체 담당자들이 경관협정 체결 기간을 인식하지 못하고 있는 경우 가 대부분인 것으로 나타났음. 2016년 기준 집계된 28곳 이후 11 곳이 협정을 체결하였으며, 이 11 곳은 옹진 7 곳, 세종 2 곳, 대전과 광양이 각 1 곳이며, 이들 중 옹진 1 곳을 제외한 곳들의 지속 여부를 확인하 였음. 이에, 2017년 기준 실질적으로 운영되고 있는 곳은 이 10 곳을 포함 총 17 곳으로 볼 수 있음.

주 2. 경관협정을 목적으로 추진된 사례는 세종 철로면 숲길마을 경관협정 (2016년 체결), 수원 거북시장길 경관협정(2012년 체결), 성대, 밤밭 문화의 거리 경관협정(2015년 체결)의 3곳에 불과하며, 그 외의 사례 는 공공주도에 의해 사업과 연계하여 추진된 것임.

주 3. 서울 구로구 개봉동 들머리 경관협정(2012년 체결), 서울 관악구 서 림동 보그니마을 경관협정(2012년 체결), 인천 옹진군 문갑도 토탈 디자인 빌리지 경관협정(2011년 체결), 인천 옹진군 백령면 심청각 진입로 주변 개선을 위한 경관협정(2012년 체결), 수원 거북시장길 경관협정(2012년 체결).

\section{References}

1. Jung, J. H. and J. J. Shin(2014) A study on the change of local-community in the process of landscape agreement focused on Bambat-SungKyunKwan University Culture Sterrt. Spring Annual Conference of AIK, 2014 34(1): 139-140.

2. Kim, J. H(2010) Governance case analysis in implementation of landscape agreement project: Case of Gwangjin-gu and Gangbuk-gu. Seoul National University.

3. Kim, M. S., H. B. Kim and Y. G. Kim(2010) A study on the implementation system of landscape agreement project: Focused on Goyang City's Landscape Agerrment Project. Journal of The Korea Landscape Council 2(1): 1-16.

4. Ko, H. J., S. J. Chung and Y. H. Son(2016) A study on the role of participants in the Suwon Gobuk Market Landscape Agreement. Journal of the Korean Institute of Landscape Architecture 44(6): 1-12.

5. Lee, C. H., J. G. Oh and J. D. Jung(2011) A study on the operation system of landscape agreement in Korea. Journal of The Architectural Institute of Korea Planning \& Design 27(6): 169-176.

6. Lee, Y. K. (2016) Achievements and assignment of landscape agreement, Architecture \& Urban space Vol. 23: 91-95.

7. Lee, Y. K. and K. M, Shim(2017) The Management and Limit of The Landscape Agreement System, auri brief No. 146.

8. Park, M. J., H. C. Ahn and S. H. Park(2010) Improving old residential neighrhoods through urban landscape agreements: A case study of Yong-Ma Community Design in Joong-Gok 4 Dong. Journal of The Architectural Institute of Korea Planning \& Design 26(7): 183-192.

9. Park, S. J., L. Sander and K. B. Kim(2015) Astudy on the effectiveness of cityscape agreement projects : Focused on Mungap Island Cityscape agreement projects. Autumn Annual Conference of UDIK, 2015: 271-277.

10. Pyon, H. S. (2010) A study on experts' role and support for effective operation of landscape agreement. Journal of The Korea Landscape Council 2(1): 17-30.

\footnotetext{
Received : 19 September, 2019

Revised : 18 October, 2019

07 November, 2019

Accepted : 07 November, 2019

3인익명 심사필
} 